[This document contains the author's accepted manuscript. For the publisher's version, see the link in the header of this document.]

\title{
The Effect of SFAS No. 131 on the Cross-Segment Variability of Profits Reported by Multiple Segment Firms
}

\author{
By Michael L. Ettredge, Soo Young Kwon, David B. Smith, and Mary S. Stone \\ University of Kansas, Korea University, University of Nebraska at Lincoln, University of Alabama
}

\begin{abstract}
Paper citation:
Ettredge, Michael. (2006) The Effect of SFAS No. 131 on the Cross-Segment Variability of Profits Reported by Multiple Segment Firms. Review of Accounting Studies, 91-117.
\end{abstract}

\author{
Keywords: \\ Segment reporting, SFAS No. 131, transparency, proprietary costs
}

\begin{abstract}
:
Our study assesses whether SFAS No. 131 improved disclosure about the diversity of multiple segment firms' operations. We find a post-SFAS No. 131 increase in cross-segment variability of segment profits, an increase in the association between reported and inherent cross-segment variability, and an increase in association between reported variability and capital market incentives to disclose. We interpret the results as evidence that SFAS No. 131 increased the transparency of segment profitability disclosures, and as indicating SFAS No. 131 allowed firms depending more on external financing to disclose more about differences in segment profitability.
\end{abstract}


The Effect of SFAS No. 131 on the Cross-Segment Variability of Profits Reported by

\title{
Multiple Segment Firms
}

\author{
Michael L. Ettredge \\ University of Kansas
}

\section{Soo Young Kwon}

Korea University

David B. Smith

University of Nebraska at Lincoln

Mary S. Stone

University of Alabama

\section{August 2005}

Send page proofs to:

Professor Michael Ettredge

School of Business

University of Kansas

1300 Sunnyside Ave.

Lawrence, KS 66045-7585

Telephone: 785-864-7537

E-mail: mettredge@ku.edu 


\title{
The Effect of SFAS No. 131 on the Cross-Segment Variability of Profits Reported by Multiple Segment Firms
}

\begin{abstract}
Our study assesses whether SFAS No. 131 improved disclosure about the diversity of multiple segment firms' operations. We find a post-SFAS No. 131 increase in cross-segment variability of segment profits, an increase in the association between reported and inherent cross-segment variability, and an increase in association between reported variability and capital market incentives to disclose. We interpret the results as evidence that SFAS No. 131 increased the transparency of segment profitability disclosures, and as indicating SFAS No. 131 allowed firms depending more on external financing to disclose more about differences in segment profitability.
\end{abstract}

Key Words: Segment reporting, SFAS No. 131, transparency, proprietary costs

JEL Classification: M41, D21, D78 


\section{The Effect of SFAS No. 131 on the Cross-Segment Variability of Segment Profits Reported by Multiple Segment Firms}

SFAS No. 131 was enacted to improve disclosure about the diversity of a firm's operations. ${ }^{1}$ Other studies investigating whether this objective was achieved compare the number of segments reported by firms before and after SFAS No. 131, and interpret an increase in number of reported segments as evidence of improved segment disclosure (e.g., Berger and Hann 2003a; Herrmann and Thomas 2000; Street et al. 2000). This approach is appropriate for firms that were managed as multiple segment firms before SFAS No. 131 but were not reported as such until after SFAS No. 131 (i.e., single to multiple segment reporters, S-M firms). It is not as well suited for firms that were managed and reported as multiple segment firms before as well as after SFAS No. 131 (i.e. continuous multiple segment reporters, M-M firms). For these firms, the effect of the change from an industry-based to management-based approach to defining reporting segments, required by SFAS No. 131, was to increase, decrease, or not change the number of segments reported. ${ }^{2}$

If one uses segment numbers as a measure of information about operating diversity, as in prior studies, SFAS No. 131 must be viewed as not improving segment disclosure for firms experiencing no changes in the number of reported segments. Similarly, SFAS No. 131 would appear to have decreased information about operating diversity for firms that decreased the number of reported segments. This is a troubling interpretation given the (subsequently documented) size and economic importance of M-M firms. We employ a different metric to assess the effect of SFAS No. 131 on disclosures of information, about the diversity of operating income across segments, by continuous multiple segment reporters. Our metric, the range of reported segment profits, captures the cross-segment variability of reported profits, 
which we argue represents diversity in operating results. ${ }^{3}$ Our use of the cross-segment variability metric is motivated by the aggregation criteria of SFAS No. 131 (paragraph 17), which are intended to dissuade multiple segment firms from aggregating operating segments with different economic characteristics as indicated by different profit margins. ${ }^{4}$ Our measure captures improvements in disclosure of operating diversity because, if firms applied the aggregation criteria as intended, the cross-segment variability of reported segment profits should have increased after SFAS No. 131. This scenario assumes managers did not use the flexibility inherent in the SFAS No. 131 management approach to transfer revenues and costs among segments, so as to conceal differences in segment profitability. ${ }^{5}$

Our analysis begins by documenting differences between M-M and S-M firms. It shows that M-M firms are more diverse, profitable and complex but less dependent on external financing than S-M firms. The M-M firms are an economically important group of firms for which the effect of SFAS No. 131 has not previously been assessed. Comparison of the number of pre- and post-SFAS No. 131 segments reported by S-M and M-M firms shows an average increase from one to three segments for S-M firms, but that the predominant effect on M-M firms was no change in number of segments or a decrease. Use of our alternative metric for assessing the effect of SFAS No. 131 - the cross-segment variability of reported profits suggests that SFAS No. 131 increased information about operating diversity, an effect that could not have been documented for M-M firms using the number of reported segments metric.

We further assess the effect of SFAS No. 131 on M-M firms by testing four hypotheses: H1: Firms revealed more about differences in segment profitability after SFAS No. 131. H2: SFAS No. 131 increased the transparency of segment profit disclosures. H3: SFAS No. 131 reduced the effect of proprietary cost incentives on segment disclosures. H4: Firms that depend 
more on external financing disclose more about differences in segment profitability after SFAS No. 131 .

We test $\mathrm{H} 1$ by estimating the change in the cross-segment variability of reported profits from the pre- to post-SFAS No. 131 periods. Univariate statistics show that a significant increase occurred, a result consistent with firms disclosing more about differences in segment profitability after SFAS No. 131. The positive coefficient of a SFAS No. 131 indicator variable in a pooled regression of pre- and post-SFAS No. 131 observations, which controls for other influences on the variability of reported segment profits, also is consistent with this interpretation.

To determine whether the increase in cross-segment profit variability is attributable to the adoption of SFAS No. 131 and to provide a basis for testing our remaining hypotheses, we develop and test models that include variables proxying for other factors that could affect the cross-segment variability of reported profits: the cross-segment variability that would exist absent incentives to conceal differences (inherent variability), proprietary costs, and market incentives to reveal value-relevant segment differences. The inclusion of proprietary cost variables is prompted by previous research (e.g., Harris 1998; Berger and Hann 2003b), which shows that firms with higher proprietary costs report fewer segments. It also is motivated by the often-stated claim that companies that disclose additional segment information suffer competitive harm (Taub 2004). The inclusion of variables for market incentives is motivated by insights from Chen and Zhang (2003) and analysis of the incentives firms needing external financing have to disclose value relevant information (Frankel et al. 1995).

$\mathrm{H} 2$ is based on the premise that a reported profit measure is more transparent if it is more strongly, and positively, associated with a measure of the inherent ('true') cross-segment variability of profits. Our primary proxy for the latter is the cross-segment profit variability of 
single segment firms in the four-digit SIC code industries corresponding to sample firms' segments. Comparison of the coefficients of separate regressions based on pre- and post-SFAS No. 131, and controlling for other factors affecting cross-segment variability, indicates a significant increase in the positive association between reported and inherent cross-segment variability. We interpret this as evidence SFAS No. 131 increased the transparency of segment disclosures.

Comparison of the coefficient of proprietary cost variables in pre- and post-SFAS No. 131 regressions shows that the negative association between cross-segment variability and proprietary cost variables continues to be significant and essentially unchanged in magnitude after SFAS No. 131. This is consistent with managers continuing to have some latitude to conceal differences in segment profitability that could be competitively harmful if disclosed. It is not consistent with $\mathrm{H} 3$.

Comparison of the coefficients of a variable reflecting a firm's need for external financing shows that the positive association between need for external financing and crosssegment profit variable is more positive after SFAS No. 131. This is consistent with firms that depend more on external financing disclosing more about differences in operating profitability after SFAS No. 131, and also with H4.

Our results are robust to experimentation with interacting variables representing competing incentives to conceal (reveal) differences in segment profitability, with elimination of high net loss segments, with adjustments to the dependent variable (cross-segment profit variability) to control for the effects of differences in segment size, and to use of different operationalizations of explanatory variables.

The remainder of the paper is organized into five additional sections. Section 1 provides background. Section 2 develops hypotheses, explains variable measurement, and 
presents our model of reported cross-segment profit variability. Section 3 describes the sample and documents differences between firms that did and did not report multiple segments prior to SFAS No. 131. Section 4 reports the results of primary tests and sensitivity analyses. Section 5 summarizes and concludes.

\section{Background}

This section contains two subsections. The first explains the intended effects of SFAS No. 131 on the usefulness and transparency of segment disclosures and the concerns of managers about the proprietary costs of segment disclosures. The second discusses the academic literature examining management's proprietary cost incentives for concealing segment information, the effects of SFAS No. 131 on the number of reported segments, and capital market incentives to reveal segment differences. This literature motivates our inclusion of proprietary cost and capital market variables in our empirical analysis of the effects of SFAS No. 131. In this section we also explain our incremental contribution to the literature.

\subsection{Institutional background}

In January 1996, the FASB and the Canadian Accounting Standards Board (FASB 1996) jointly issued an exposure draft (ED) on segment reporting calling for firms to disclose information on the basis used internally to evaluate performance and to allocate resources to business units (i.e., the management approach to identifying segments). The FASB received 220 letters of comment on the ED. Responding financial statement users favored the management approach, asserting that it would provide insights into the risks and opportunities facing each part of the business, better align segment footnote disclosures with management's discussion and analysis, and reduce the incremental cost of segment reporting. 
In contrast to users, the majority of commenting managers opposed the management approach, arguing that it would result in disclosure of information that would be competitively harmful. They contended that public companies would be required to disclose more detailed product information than private companies or foreign competitors, and that powerful competitors would take advantage of more detailed segment information. ${ }^{6}$ Matrix Service Company, for example, contended: "The disclosure of our gross margins at this level of detail would virtually disclose our entire pricing structure to our competition" (ED response letter to FASB dated June 14, 1996).

The Board responded to concerns about potential competitive harm by modifying aggregation criteria, adding quantitative materiality thresholds, and changing certain disclosure requirements. SFAS No. 131, which was issued in June 1997, includes these changes (paragraph 111). It is intended "to help users of financial statements: (a) better understand the enterprise's performance, (b) better assess its prospects for future net cash flows, and (c) make more informed judgments about the enterprise as a whole" (SFAS No. 131, paragraph 3).

\subsection{Literature review}

\subsubsection{Proprietary cost incentives to conceal}

Harris (1998) uses a pre-SFAS No. 131 sample of multiple segment firms to estimate the relation between management's decision to report operations in a given industry as a segment and two measures of proprietary costs: a four-firm concentration ratio and a measure of the speed of profit adjustment. ${ }^{7}$ Her results show that operations in less competitive (high proprietary cost) industries are less likely to be reported as industry segments. Evidence consistent with SFAS No. 131 requiring disclosure of proprietary information is provided by Ettredge et al. (2002), which shows that firms most likely to suffer competitive harm from more 
disaggregated segment disclosure experienced significant, negative abnormal returns on dates of FASB news releases prior to the issuance of SFAS No. 131.

Berger and Hann $(\mathrm{BH}, 2003 \mathrm{~b})$ investigate whether firms that increased the numbers of their segments when adopting SFAS No. 131 had higher proprietary costs. They also investigate whether the decrease in market value (relative to sales) for firms reporting more segments after SFAS No. 131 is attributable to the release of proprietary information to competitors or to revealing agency problems. The firms in their sample disclose multiple segments after the adoption of SFAS No. 131 but not necessarily before. Their model includes three measures of proprietary costs: firm-level industry-adjusted abnormal profits, rate of deterioration in abnormal profits ${ }^{8}$, and range of segment profit margins. They find a significant positive relation between pre-SFAS No. 131 aggregation and each of their profitability measures. They interpret their findings as evidence pre-SFAS No. 131 aggregation was greater among firms for which the proprietary costs of additional disaggregation were higher, i.e., ones for which disaggregation would have revealed more detailed information about profit opportunities.

Although BH (2003b) present evidence consistent with SFAS No. 131 causing some firms to disclose proprietary data, they find only weak evidence that the increase in the number of reported segments after SFAS No. 131 resulted in competitive harm, when measured as a decrease in abnormal profits. One explanation for the absence of observed competitive harm is that the time period of BH's study was too short for competitors to take advantage of the SFAS No. 131 disclosures by entering new or related lines of business. Another is that firms might have increased the number of reported segments without revealing significantly more about differences in segment profitability, an outcome that would occur if the disclosed profit margin 
of the newly disclosed segments differed little from the profit margins of previously disclosed segments.

\subsubsection{Capital market incentives to reveal}

Managers have incentives to reveal as well as to conceal information (Fields et al. 2001, 292). The expectation that more informative disclosures increase liquidity and reduce the cost of capital (Verrechia 2001) provides incentives for firms that rely heavily on capital markets for financing to credibly disclose value-relevant information (Frankel et al. 1995).

Chen and Zhang's (2003) analysis, of capital market incentives for two-segment firms to disclose segment differences, demonstrates the value-relevance of segment disclosures. Chen and Zhang (2003) shows that the market value of a two-segment firm can be determined using corporate-level data when a firm's operating segments are equally profitable and have equal growth opportunities. When the operating segments have divergent profitability, however, valuation requires not only firm-level accounting data to convey information about overall firm operations, but also segment-level data to convey differences between the segments (p. 398). In such a setting, providing more information about segment differences could increase firm value. ${ }^{9}$

\subsubsection{Contribution to the literature}

Our study differs from earlier and contemporaneous studies investigating the effect of SFAS No. 131 on segment disclosures in two important ways. First, our findings show that our measure of information about differences in segment performance (cross-segment variability of reported profits) provides inferences about the effects of SFAS No. 131 that are not provided by other studies' measures that are based on the change in number of disclosed segments between the pre-and post-SFAS No. 131 periods. Second, we concentrate on firms that disclosed multiple segments both before and after adopting SFAS No. 131. Previous studies of 
SFAS No. 131 (e.g., Berger and Hann 2003a; Herrmann and Thomas 2000; Street et al. 2000) used samples composed mostly of relatively small companies that appear to have been managed as multiple segment firms in the pre-SFAS No. 131 period but disclosed only a single segment in their financial statements (i.e., single-to-multiple segment firms or S-M firms). It seems indisputable that SFAS No. 131 increased the transparency of operating information disclosed by these S-M firms due to the greater disaggregation of their operating information. What is not clear is the effect SFAS No. 131 had on the segment information disclosed by larger, pre-SFAS No. 131 multi-segment disclosing companies (i.e., 'multiple-to-multiple' segment or M-M firms) that made up a relatively small portion of the prior studies' samples. Descriptive evidence provided later in the paper documents the economic importance of M-M firms and how these firms differ from S-M firms.

The effect of our focus on M-M firms deserves additional discussion. One sample selection criterion used in some prior studies is that the companies be multiple-segment disclosers in the post SFAS No. 131 period. This criterion results in the inclusion of large numbers of S-M firms in samples. For such firms, SFAS No. 131's effect is always an increase in the number of segments (from one to two or more). Thus, including large numbers of S-M companies in samples generates results suggesting that SFAS No. 131 generally increased numbers of segments disclosed. However, as we show below, for M-M firms SFAS No. 131 resulted in increases, decreases, or no changes in numbers of segments disclosed. This suggests that M-M firms should be studied separately, and that a different measure of improved information about operating diversity is required for these firms.

\section{Hypotheses and Empirical Model Development}




\subsection{Hypotheses}

SFAS No. 131 prohibits aggregation of segments with different economic characteristics, such as profit margins, because they are likely to have different long-term financial performance. If preparers who previously aggregated segments with dissimilar profit margins interpreted SFAS No. 131 as prohibiting them from continuing to do so, implementation of SFAS No. 131 would have increased the cross-segment variability of reported profits. ${ }^{10}$ This line of reasoning provides the basis for our first hypothesis, which is stated in alternative form.

H1: SFAS No. 131 increased the cross-segment variability of reported profits.

The cross-segment variability of reported profits provides potentially useful information about differences in segment profitability. A transparent measure of such differences would reflect the 'true' or inherent differences in segment profitability (i.e., the differences that would exist because of differences in economic characteristics.) Conversely, a transparent measure would not have been manipulated to conceal inherent differences in segment profitability. This line of reasoning provides the basis for our second hypothesis, which is stated in alternative form.

H2: The positive association between the cross-segment variability of reported profits and variables proxying for inherent variability increased (became more positive) after SFAS No. 131.

SFAS No. 131 changed the methodology for identifying reportable segments but did not eliminate management's incentives to conceal differences in segment profitability. If the change in methodology made it more difficult for managers to conceal differences in reported segment profits that could cause competitive harm, the explanatory ability of variables representing managers' incentives to conceal (i.e. proprietary costs) would have decreased after 
SFAS No. 131. Following this line of reasoning, we test the following hypothesis, which is stated in alternative form.

H3: The negative association between the cross-segment variability of reported profits and variables proxying for proprietary cost decreased (became less negative) after SFAS No. 131.

Competition for low cost external financing provides incentives for firms to disclose value-relevant information. If, as Chen and Zhang's (2003) analysis suggests, information about differences in segment profitability is value-relevant and the methodology of SFAS No. 131 improves disclosure about difference in segment profitability, the explanatory ability of variables reflecting firms' reliance on external financing should increase after SFAS No. 131. Following this line of reasoning, we test the following hypothesis, which is stated in alternative form.

H4: The positive association between the cross-segment variability of reported profits and variables proxying for reliance on external financing increased (became more positive) after SFAS No. 131.

\subsection{Empirical Model Variables}

Our empirical model includes variables representing the constructs of our conceptual model and four control variables. This section explains the choice and operationalization of the model's variables.

\subsubsection{Cross-segment variability of reported profits}

We use the range of reported segment profits (ReptdProfVar) because it provides a valid measure of variance for as few as two to nine observations (Gitlow et al. 1989). ${ }^{11}$ The segment profit measure, return on sales (ROS), is computed using reported segment income from 
operations in the numerator, the measure of segment profit reported by the largest number of sample firms. $^{12}$

\subsubsection{Inherent cross-segment profit variability}

Inherent cross-segment profit variability is determined by the underlying business reporting unit activities in which a firm engages. For example, large inherent variability would be expected for firms with business reporting units that are in different phases of the product life cycle. In such firms, some business units would have operating margins similar to growth firms while others would have operating margins similar to mature firms. We assume inherent differences are beyond management's control and that, absent intervention or measurement error, the reported and inherent range of reported segment profits for a given firm would be equal. We expect the reported and inherent range of reported segment profits to be positively correlated. The extent of this association reflects the 'transparency' of the reported segment earnings data.

Because the inherent range of segment profits is not observable, we use two proxies for the underlying construct. We begin by computing the annual return on sales (equal to earnings before interest and taxes, divided by sales revenue) for all single segment firms operating in those four-digit SIC code industries in which a sample firm operates, and which correspond to segments that it discloses. For a firm disclosing $\mathrm{K}$ segments in a year, Compustat matches each segment to one of the firm's $\mathrm{N}$ four-digit industries, based on the firm's descriptions of its segments. We compute the mean of the return on sales for single segment firms within each of the $\mathrm{K}$ four-digit SIC code industries in which a sample firm operates, and that Compustat identifies with its business segments. Each of the $\mathrm{K}$ annual means is weighted by the relative size of the firm's segment corresponding to the given SIC code industry. The weight equals the segment's sales, divided by corporate sales. Then we compute the yearly range of the K 
weighted means (highest weighted mean ROS minus lowest weighted mean ROS). We designate this variable InherentProfVar. Because this variable is computed using data for multiple, single segment firms in each industry, it is likely to reflect the inherent cross-sectional variability of profits in each sample firm's portfolio of industries. ${ }^{13}$

Firms engaging in diverse business activities are likely to have smoother firm-level variability of profits over time due to a 'portfolio' effect. In a given year, unusually high profitability in one activity (industry) tends to be offset by unusually low profitability in another, uncorrelated industry. Thus, reduced firm-level profit variance over time results from greater activity-level profit variance within each year. Our variable Diverse reflects the diversity of the industries in which a firm operates. It is the number of the firm's different twodigit SIC code industries. For example, Diverse would be coded as two for a firm operating in SIC industries $2819,2899,3334$, and 3355 , and as one for a firm operating only in SIC industries 2819 and $2899 .^{14}$

\subsubsection{Disclosure rule}

Managers' responses to the Exposure Draft preceding SFAS No. 131 indicate that they expected the proposed standard to make it more difficult to conceal differences in segment profitability. Nonetheless, the extent of discretion left to managers in applying SFAS No. 131 makes it unlikely firms' ability to suppress differences in segment profitability has been totally eliminated. ${ }^{15}$ Our model includes an indicator variable, FAS131, which is coded 'one' in years 1998-2000, and coded 'zero' in years 1994-1996. Year 1997 is omitted from the pooled data to avoid the potential confounding effect of early adoption of SFAS No. 131, or of actions taken to prepare for adoption. We expect the coefficient of the indicator variable to be positive and significant if SFAS No. 131 makes it more difficult for managers to engage in cross-segment profit smoothing. 


\subsubsection{Proprietary costs incentives to conceal}

Consistent with proprietary cost explanations of segment disclosures, research indicates that, prior to SFAS No. 131, fewer segments were reported by firms with higher abnormal profitability (Berger and Hann 2003b) and by firms operating in more concentrated industries (Harris 1998). ${ }^{16}$ AbnProf is an industry-adjusted measure of profits: ${ }^{17}$

$$
\begin{aligned}
& R O A_{i t}=I B E I \div 0.5 \times\left(T A_{i t-1}+T A_{i t}\right) \\
& A_{v g R O A_{i t}}=\left(R O A_{i t}+R O A_{i t-1}+R O A_{i t-2}\right) \div 3 \\
& \text { AbnProf }_{i t}=\text { AvgROA }_{i t}-1 /(\mathrm{K}-1) \sum_{k \neq i, k=1, K} \operatorname{AvgROA}_{k t} .
\end{aligned}
$$

$R O A$ is defined as income before extraordinary items, divided by average total assets. The three-year average of $R O A$ is denoted AvgROA. Abnormal profitability is computed as a sample firm's AvgROA minus the mean of AvgROA across $\mathrm{K}$ industries. The $\mathrm{K}$ industries are those four-digit SIC code industries that Compustat identifies with the sample firm's K disclosed business segments. ${ }^{18}$ Firms with high AbnProf must have one or more segments that are highly profitable. We expect the coefficient of AbnProf to be negative, reflecting incentives to conceal information about differences in segment profitability that could help competitors. However, it is possible that managers of unusually profitable firms have greater capital markets incentives to reveal the sources of their firms' profitability. Given both proprietary cost incentives to conceal abnormal profitability, and capital market incentives to reveal, the resulting coefficient of AbnProf could be positive or negative. Our expectation of a negative coefficient assumes that capital market incentives to reveal are largely captured by the ExternalFin variable introduced below. 
Harris (1998) argues that the threat of competitive entry depends not only on the magnitude of profits at risk but also on the ability of a firm's competitors to attack such profits. In a highly competitive line of business, numerous, relatively small producers earn the same competitive returns. ${ }^{19}$ There are no abnormal profits to protect and therefore no incentive to conceal information. The setting in which a firm has incentives to conceal is one in which the firm seeks to protect abnormal profits from a few powerful current or potential competitors. The variable we use to capture this aspect of incentives to conceal is a weighted-average fourfirm concentration ratio for the industries in which a firm operates, Concentration. For a firm disclosing $\mathrm{K}$ segments in a year, we compute a concentration ratio for each of $\mathrm{K}$ industries that Compustat matches to the disclosed segments. Concentration is the weighted average of the K matched-industry concentration ratios, with each ratio weighted by the appropriate segment's annual revenue, divided by corporate annual revenue. Using the weighted average of the $\mathrm{K}$ concentration ratios assumes that managers are concerned about competitors in all of a firm's industries, in proportion to the importance of each industry to the firm as measured by segment revenues. $^{20}$

\subsubsection{Capital market incentives to reveal}

We control for managers' capital market incentives to reveal cross-segment differences in profitability using a variable representing a firm's need for external financing. For a given year, ExternalFin is the net amount of capital a firm raises through debt or equity issuances in the subsequent two years. It is calculated as the two-year sum of net equity financing and net debt financing, from the statement of cash flows, divided by average total assets:

$$
\begin{aligned}
\text { ExternalFin }_{t}= & {\left[\Sigma_{T=t+1, t+2}\left(E Q T Y \_I S S_{T}-E Q T Y \_R E P_{T}-D I V_{T}\right)\right.} \\
& \left.+\Sigma_{T=t+1, t+2}\left(L T D \_I S S_{T}-L T D \_R E P_{T}\right)\right] \div 0.5 \times\left(T A_{t-1}+T A_{t}\right)
\end{aligned}
$$


where:

$E Q T Y \_I S S_{T}=$ cash proceeds from the sale of common and preferred stock for $T=t+1$ and $t+2$

$E Q T Y \_R E P_{T}=$ cash payments for the purchase of common and preferred stock for $T=t+1$

$$
\text { and } t+2 \text {, }
$$

$D I V_{T}=$ cash payments for dividends for $T=t+1$ and $t+2$,

$L T D \_I S S_{T}=$ cash proceeds from the issuance of long-term debt for $T=t+1$ and $t+2$,

$L T D \_R E P_{T}=$ cash payments for long-term debt reductions (Compustat item \#114) for $T$

$$
=t+1 \text { and } t+2 \text {. }
$$

The coefficient of ExternalFin should be positive, indicating that firms that rely more heavily on external capital are more willing to reveal the segments that contribute most to firm-level profitability.

\subsubsection{Control variables}

We include four control variables in our model: firm size, firm complexity, number of reported segments, and segment aggregation. Firm size and complexity could influence segment disclosures in conflicting ways. Respondents to the Exposure Draft preceding SFAS No. 131 asserted that large, complex firms have greater ability to define reportable segments and to develop cost allocation schemes that conceal differences in segment profitability. This response suggests a negative association of reported cross-segment variability with firm size and complexity. A positive association is suggested by the literature asserting that large, complex firms have capital market incentives to disclose operating diversity. Our size measure is the natural logarithm of firm sales, Size. Our measure of firm complexity, Complexity, is the 
square root of the sum of the number of products a firm produces and the number of geographic areas in which it operates. We do not specify a sign expectation for either variable.

Prior research (e.g., Harris 1998) indicates that managers choose to disclose fewer segments in order to reduce proprietary costs. The number of reported segments also can reflect structural changes, such as acquisitions and divestitures, as well as changes in segment disclosure rules. In addition, statistically, the range of a random variable is expected to increase as the number of independent observations used to compute the range increases. Thus our dependent variable, ReptdProfVar, should be positively associated with NumberSegs, the number of reported segments that contribute ROS observations for computation of annual ReptdProfVar. Because we estimate our model using pooled data for firms reporting different numbers of segments, we include NumberSegs, number of reported segments per year, as a control variable. NumberSegs arguably reflects a mixture of underlying factors, including managers' attempts to conceal segment information, and the segment reporting rules in effect. To the extent NumberSegs reflects reporting requirements in effect, employing this variable allows us to determine whether SFAS No. 131 increased variability of segment ROS other than through its effect on number of segments.

Another control variable captures the effect of industry aggregation on the variability of ROS across reported segments (our dependent variable.) Most firms report a smaller number of segments than the number of four-digit SIC code industries in which they operate. Such aggregation decreases the variability of $R O S$ across reported segments by making each segment's ROS the outcome for a portfolio of different industries. Proxy SegAggregation is computed as the number of four-digit SIC codes that Compustat assigns a firm, divided by the number of segments the firm reports each year, NumberSegs. Because variable SegAggregation includes NumberSegs, employing variable SegAggregation again helps us to 
determine whether SFAS No. 131 increased variability of segment ROS other than through its effect on number of segments. We expect the coefficient of SegAggregation to be negative.

\subsection{Empirical models}

Our primary model is:

$$
\begin{aligned}
\text { ReptdProfVar }_{\mathrm{it}} & =\alpha_{0}+\beta_{1} \text { InherentProfVar }_{\mathrm{it}}+\beta_{2} \text { Diverse }_{\mathrm{it}}+\beta_{3} \text { FAS13 }_{\mathrm{it}}+\beta_{4} \text { AbnProf }_{\mathrm{it}} \\
& +\beta_{5} \text { Concentration }_{\mathrm{it}}+\beta_{6} \text { ExternalFin }_{\mathrm{it}}+\beta_{7} \text { Size }_{\mathrm{it}}+\beta_{8} \text { Complexity }_{\mathrm{it}} \\
& +\beta_{9} \text { NumberSegs }_{\mathrm{it}}+\beta_{10} \text { SegAggregation }_{\mathrm{it}}+\varepsilon_{\mathrm{it}}
\end{aligned}
$$

where:

ReptdProfVar = range of a firm's segment returns on sales for each year: the largest return on sales minus the smallest. Return on sales equals a segment's operating profits, as defined by the firm, divided by total segment sales revenue.

InherentProfVar $=$ range of the $\mathrm{K}$ weighted means (highest weighted mean ROS minus lowest weighted mean $R O S$ ) for single-segment firms within each of the $\mathrm{K}$ four-digit SIC code industries in which a sample firm operates, and that Compustat identifies with its business segments. Each of the $\mathrm{K}$ annual means is weighted by the relative size (sales) of the firm's segment corresponding to the given SIC code industry. $(+)$.

Diverse $\quad=$ number of different two-digit SIC industries in which firm operates. $(+)$.

FAS131 = equals 'one' in each of the years since SFAS No. 131 was issued (19982000) and 'zero' in preceding years (1994-1996). (+).

AbnProf = sample firm's AvgROA minus the mean of AvgROA across $\mathrm{K}$ industries. AvgROA is the three-year average of ROA (for preceding years). ROA is defined as income before extraordinary items (IBEI) divided by average total 
assets. The $\mathrm{K}$ industries are those four-digit SIC code industries that

Compustat identifies with the sample firm's K disclosed business segments.

$(-)$.

Concentration = weighted average of four-firm concentration ratios for the four-digit SIC code industries matched with the firm's disclosed segments by Compustat. Each industry concentration ratio is weighted by the ratio of the matched segment's revenue divided by corporate revenue for that year. (-).

ExternalFin $=$ the sum over the succeeding two years of net equity financing and net debt financing, from the statement of cash flows, divided by average total assets. $(+)$.

Size $\quad$ = natural logarithm of total corporate revenues for each year. (?).

Complexity $=$ square root of the sum of the number of products that a firm produces and the number of geographic areas in which the firm operates. The number of products is increased by 'one' if a disclosed principal product has sales. The number of geographical areas is the number of non-zero GARE data items in the Segment Customers File. (?).

NumberSegs = number of reported segments disclosed in a given year. $(+)$. SegAggregation $=$ number of four-digit SIC codes Compustat assigns a firm, divided by the number of segments the firm reports each year. (-).

We estimate the model using data pooled over years. An approach recommended by FamaMacBeth (1973) is used to mitigate overstatement of coefficient p-values that might occur when using data that are pooled across years. ${ }^{21}$

\section{Sample and Data}


Our sample selection (documented in table 1) begins with all firms having business segment data available on the Compustat Segment Item Value File ${ }^{22}$ for any year from 19942000, a period including both pre- and post-SFAS No. 131 segment disclosures (row A). We eliminate firms that did not disclose: two or more segments post-SFAS No. 131, segment operating income or segment sales, and required financial statement information on the Compustat Industrial Annual File (resulting in the samples shown in rows B and C). The firms that are left have valid observations before and after SFAS No. 131 (the sample shown in row D). Approximately two-thirds of these firms did not report multiple segments until after SFAS No. 131 (the sample in row E, referred to as S-M firms). ${ }^{23}$ The remaining third of the firms reported multiple segments before and after SFAS No. 131 (the sample shown in row F, referred to as $\mathrm{M}-\mathrm{M}$ firms). The number of $\mathrm{M}-\mathrm{M}$ firms, reporting two or more segments and having the required financial statement data, ranges from a minimum of 1,033 in 1994 to a maximum of 1,293 in 1996.

[Insert Table 1 about here]

Past research has concentrated on the increase in the number of segments companies disclose as a result of SFAS No. 131. This focus is warranted for S-M firms. However, it can result in misleading inferences about the effects of SFAS No. 131 for M-M firms. Table 2 reports descriptive statistics for the total sample, S-M firms and M-M firms for size proxies and explanatory variables from our main empirical model. It documents size and other important differences between S-M and M-M firms, by showing that the market capitalization of the average M-M firm is four times greater than that of the average S-M firm, while average total assets are five times greater. Means and medians are significantly different for all explanatory variables. M-M firms are more diverse, profitable, and complex, but less dependent on external 
financing than S-M firms. These data provide evidence that the average M-M firm is different and arguably more economically important than the average S-M firm.

\section{[Insert Table 2 about here]}

Table 3 provides evidence on the number of segments and reported profit variability for S-M and M-M firms. The left-hand columns report changes in the number of segments using the number of pre-SFAS No. 131 segments as the grouping criterion. Consistent with earlier studies (e.g., Berger and Hann 2003a, Herrmann and Thomas 2000; Street et. al. 2000), the mean number of segments increased significantly for S-M firms, from one to over three, in the post period. Results are more mixed for M-M firms. M-M firms with two, three or four segments in the SFAS No. 131 period experienced significant increases in the mean number of segments. However, the increases are less than one segment (about one-half segment) for each group. This suggests that changes in segments for the under-five groups were not uniformly increasing. For companies disclosing five segments in the pre-SFAS No. 131 period, the data do not reject the null of no change. Finally, for the greater-than-five segment group, there is a significant decrease in the mean number of reported segments. ${ }^{24}$ Given that the median and mean numbers of segments for M-M firms in the pre-SFAS No. 131 period equal and exceed five (see table 2), our table 3 results indicate that the predominant effect of SFAS No. 131 on M-M firms was no change in segment numbers, or even decreases. The reasoning employed in prior studies would suggest that SFAS No. 131 caused no change (or a decline) in the information provided by segment disclosures for companies reporting five (or more than five) segments in the pre-SFAS No. 131 period.

Table 3 also reports changes in ReptProfVar. These results lead to somewhat different conclusions about SFAS No. 131's effects on disclosure by M-M companies. The variability of segment earnings does not significantly increase in the post-SFAS No. 131 period for M-M 
companies reporting two or three segments in the pre-SFAS No. 131 period, even though their mean numbers of segments increased. On the other hand, the variability of segment profits increases significantly for the more numerous companies reporting four or more segments in the pre-SFAS No. 131 period. Particularly striking is the fact that variability of segment profits, ReptProfVar, increases significantly for firms reporting six or more segments prior to SFAS No. 131, even though mean numbers of segments decreased. ${ }^{25}$ These results suggest that the use of ReptProfVar, rather than changes in numbers of segments, leads to some differences in inferences about SFAS No. 131's effects on segment disclosure quality (i.e., information about operating diversity). ${ }^{26}$

[Insert Table 3 about here]

Table 4 reports means, medians and standard deviations for the dependent variable, cross-segment variability of reported profits (ReptProfVar) for M-M firms. ${ }^{27}$ We use this variable to test our hypotheses. Observations from 1997 are omitted from analyses of pooled data so that results are unaffected by early adoptions of SFAS No. $131 .^{28}$ Means and maximums greater than 1.0 occur because some firms report negative as well as positive segment profits. ${ }^{29}$ Consistent with $\mathrm{H} 1$, the variability of reported segment profits increased from the pre-SFAS No. 131 period (1994-1996) to the post-SFAS No. 131 period (1998-2000). All else equal, this is consistent with SFAS No. 131 expanding information about differences in the operating gross margins of segments of large, complex firms (M-M).

[Insert Table 4 about here]

Taken together tables 1 through 4 provide evidence that a researcher likely would draw different conclusions, about the effects of SFAS No. 131, when using a sample of S-M and MM firms combined, versus analyzing the groups separately. Our research design allows us to test whether M-M firms revealed more about differences in segment profitability after 
switching from the industry to management approach of computing segment profits. Focusing on firms reporting multiple segments is consistent with Harris (1998) but is different from Berger and Hann (2003a and 2003b), whose samples also include firms that did not report multiple segments until after SFAS No. 131. Subsequent tables pertain only to M-M firms.

\section{Results}

\subsection{Results for Cross-Sectional Model of Cross-segment Profit Variability}

Table 5 provides evidence on the explanatory power of our empirical model, estimated on a (1) pooled and (2) year-by-year basis. Table 5 also tests H1, using FAS131 as the test variable. The coefficients in the column labeled "Pooled" are estimated using pooled pre- and post-SFAS No. 131 data. The coefficients in the columns labeled "Year-by-year" are based on annual regressions. In the latter, the t-statistics for the means of coefficients (across years) are Fama-MacBeth (1973) adjusted. The adjustment mitigates the overstatement of coefficient pvalues that might occur when using data that are pooled across years. The "Year-by-year' estimates provide comparisons with the pooled sample results that allow us to cross-check the significance levels of independent variables with the exception of FAS 131. Table 5 indicates that F-statistics for both the pooled and year-by-year regressions are significant and that the signs of the variables are as predicted except for that of Diverse in the pooled regression.

The estimated coefficients for InherentProfVar are positive and significant as expected. The estimated coefficients for variable Diverse are mixed, suggesting that this metric is less useful proxy for inherent variance. The positive and significant coefficient of FAS131 indicates an increase in the cross-segment variability of reported profits subsequent to the adoption of SFAS No. 131. This is consistent with $\mathrm{H} 1$ and suggests that use of the 'management approach' to defining segments is associated with a wider range of reported segment profit margins and so 
appears to provide investors with additional information that would not have been available had firms continued to report using the industry approach. The fact that FAS131 is significant even though a control for the number of segments reported (NumberSegs) is included in the models indicates that SFAS No. 131 increased the variability of reported profits other than through its effect on numbers of segments reported.

The coefficients of the proprietary cost variables (AbnProf and Concentration) are negative and significant. ${ }^{30}$ This is consistent with proprietary costs providing incentives for management to conceal differences in segment profitability, and is consistent with the results of other studies using alternative measures of segment disclosure aggregation, and different dependent variables (e.g., Harris 1998; Berger and Hann 2003b). The consistently significant and positive coefficient for external financing (ExternalFin) suggests that firms facing stronger capital market incentives (i.e., those depending more heavily on external financing) are willing to reveal more about differences in segment profitability. ${ }^{31}$

The pooled regression results for the control variables also are consistent with expectations (when specified), with the exception of Complex, which is not significant. The consistently significant and negative coefficients for control variable Size are consistent with ED respondents' claims that larger firms are better able to conceal differences in segment profits. Control variable SegAggregation reflects the extent to which economic activities are aggregated into business segments for reporting purposes. As expected, coefficients are negative and significant, suggesting that higher levels of aggregation are associated with greater concealment of differences in segment profitability. The year-by-year regression results with Fama-MacBeth adjusted t-statistics provide evidence that generally is consistent with those of the pooled regression. 


\subsection{Investigation of Coefficient Shifts from the Pre- to the Post-SFAS No. 131 Periods}

Table 6 shows results for separate regressions using pre- and post-SFAS No. 131 data. The objective is to determine whether our basic model has explanatory power in both the preand post-SFAS No. 131 periods, and whether the association between reported variability and individual explanatory variables changes in the direction consistent with SFAS No. 131 increasing the explanatory power of proxies for inherent variability $(\mathrm{H} 2)$ and reliance on external financing $(\mathrm{H} 4)$, but decreasing the explanatory power of proprietary cost proxies (H3). The table indicates the signs expected for each t-statistic (Test of Difference) relevant to tests of hypotheses $\mathrm{H} 2$ and $\mathrm{H} 3$. Positive shifts in the coefficients relating reported variability to proxies for inherent variability would be consistent with increased transparency and with H2. Decreases in the association between reported variability and proxies for proprietary costs (i.e., positive shifts in the coefficients, bringing them closer to zero) would be consistent with H3. A positive shift in the coefficient of the external financing variable would be consistent with SFAS No. 131 improving the ability of managers to reveal cross-segment variability if desired and with H4. ${ }^{32}$

[Insert table 6 about here]

Our proxies for inherent variability are InherentProfVar in model (3a) and Diverse in model (3b). The dependent variable in both models is ReptdProfVar. We expect a positive shift in the coefficients of both variables if SFAS No. 131, consistent with H2, increased the transparency of segment profit disclosures. In the first model, the coefficient of variable InherentProfVar is positive and differs from zero in both the pre- and post-periods. The coefficient becomes more positive in the post-period, and the shift in the coefficient differs significantly from zero. The positive coefficient of variable Diverse in model ( $3 \mathrm{~b})$ does not differ from zero in the pre- period, but does in the post-period. The positive coefficient shift is 
significant. These results suggest that adoption of SFAS No. 131 increased the transparency of segment profit disclosures, a result consistent with $\mathrm{H} 2$.

In table 6, the coefficients for AbnProf are consistently significant and negative in both periods for both models. The insignificance of the shifts in slope coefficient from the pre- to post-period indicates that SFAS No. 131 did not affect this variable's association with variance of segment profitability. The coefficients of the other proprietary cost variable (Concentration) also are negative and significant in both the pre- and post-SFAS No. 131 periods. Similarly, the shifts in the coefficients across periods are not significant. These results are not consistent with H3. Combined with our findings that the cross-segment variability of reported segment profits increased after the effective date of SFAS No. 131, they suggest that mandated use of the management method improved transparency of segment profitability, but did not eliminate management's ability to conceal competitively harmful cross-segment differences.

The positive association between the dependent variable and the need for external financing is significantly different from zero in both the pre- and post-periods. Consistent with H4, the coefficients increase from the pre- to post-SFAS No. 131 periods. Changes also occur in control variables. The coefficient for variable Size becomes more negative after adoption of SFAS No. 131, indicating that larger firms disclosed less variability in the post- period, other things equal. In contrast, the coefficient for variable Complex becomes less negative after adoption of SFAS No. 131. The coefficient of NumberSegs becomes less positive in the postperiod. Finally, the coefficient of SegAggregation does not change from pre- to post-SFAS No. 131.

In summary, table 6 provides evidence consistent with $\mathrm{H} 2$ and $\mathrm{H} 4$, but not consistent with H3. In general, proxies for inherent variability and for high external financing are more strongly associated with the dependent variable in the post- period. Coefficients of proxies for 
proprietary cost incentives to conceal variability do not change significantly in the post period, while control variables tend to explain somewhat less in the post- period (as captured by slope coefficients and significance levels).

\subsection{Sensitivity Analyses}

Managers' incentives to conceal information about the profitability of specific segments could vary. For example, some managers may have incentives to conceal information about a high profit segment (i.e., reduce the range of reported segment profits) only if the high profit segment contributes significantly to overall corporate-level profits (i.e., accounts for a large percentage of corporate revenues). Arguably, such managers would be unconcerned about concealing information if the most profitable segment was small and contributed little to overall corporate profit. The quantitative thresholds of SFAS No. 131 make it unlikely that firms disclose information for segments small enough to be considered immaterial. ${ }^{33}$ Nonetheless, an empirical question remains as to whether our results hold for alternative versions of ReptdProfVar, especially versions that are size-adjusted. We investigate this possibility by conducting sensitivity analyses using alternative specifications of ReptProfVar.

Table 7 provides descriptive statistics for three alternative measures. ReptdProfVar_LrgAvg is the difference between the ROS of the largest segment and the mean ROS across segments. This dependent variable captures the difference in profitability between the segment with the largest revenue contribution and the mean ROS of other segments. The measure will be negative when the ROS of the largest segment is less than the average of segment ROS. ReptdProfVar_Xsml is the range of a firm's ROS after dropping the segment with smallest segment revenues. This alternative specification of the cross-segment variability of profit margins explicitly takes into account segment size by removing the effect of segments that are too small to protect, or that contribute little to corporate income. Finally, 
ReptdProfVar_Le1 is the range of a firm's segment ROS with truncation at 1 if the value is greater than 1. This final measure removes potential outlying segment profit margins by restricting the range calculation to a 'normal' range of profit margins.

We calculate t-statistics and Wilcoxon z-statistics for a comparison of pre- and post SFAS No. 131 measures of each alternative. Table 7 indicates that the differences are in the direction anticipated and significant for all three alternative specifications. These results provide support for our conclusion that the change in ReptProfVar is related to the adoption of SFAS No. 131 rather than to the way we compute cross-segment profit variability.

[Insert Table 7 about here]

We re-estimate our primary model (table 5) by replacing ReptProfVar with each alternative dependent variable discussed above. Two columns are presented for each version of the dependent variable: one for a pooled model and the other for the year-by-year model. Results, reported in table 8 , are consistent with results for $\mathrm{H} 1$ reported previously. The positive and significant coefficients of FAS131 using the three variants of ReptProfVar, and for both models, indicate an increase in the cross-segment variability of reported profits subsequent to adoption of SFAS No. 131, which is consistent with H1.

[Insert Table 8 about here]

In summary, our sensitivity analyses indicate our results are not sensitive to three alternative specifications of ReptdProfVar that adjust for segment size, and/or that truncate the effects on the dependent variable of unusually large segment profits and losses. These results strengthen the support for our conclusion that multiple segment firms revealed more about difference in segment profitability and provided more transparent segment disclosures after adopting SFAS No. 131. 


\section{Summary and Conclusions}

The objective of our study is to assess the effect of SFAS No. 131 on the segment profitability disclosures of the large, complex firms that reported multiple segments before as well as after SFAS No. 131. Our analysis begins by documenting economic differences between firms that reported multiple segments throughout the test period (continuous multiple segment reporters, M-M firms) and those that did not report multiple segments until after SFAS No. 131. We find that M-M firms are larger and more complex, and that many of them did not increase the number of reported segments after SFAS No. 131.

Assessing the effect of SFAS No. 131 on these firms by comparing the number of segments reported before and after enactment of the statement, as has been done in earlier studies (e.g., Herrmann and Thomas 2000; Street et al. 2000), would lead us to conclude the switch from the industry to management approach to identifying segment required by SFAS No. 131 did not improve information about operating diversity for the majority of M-M firms. Rather than prematurely draw this conclusion, we employ an alternative metric - the crosssegment variability of reported profits - to assess the effect of SFAS No. 131 on M-M firms. Our use of this metric is motivated by criteria in SFAS No. 131 that are intended to discourage M-M firms from aggregating segments with different economic characteristics such as profitability. If firms used the SFAS No. 131 aggregation criteria as intended, the crosssegment variability of reported segment profits should have increased after SFAS No. 131.

We document an average increase in the cross-segment variability of reported profits of M-M firms after SFAS No. 131. To determine whether this increase is attributable to the adoption of SFAS No. 131, we develop and test models that also include other factors that could affect the cross-segment variability of reported profits: the cross-segment variability that would exist absent incentives to conceal differences (inherent variability), proprietary costs, 
and market incentives to reveal value-relevant segment information. We find a post-SFAS No. 131 increase in the association between proxies for reported and inherent cross-segment profit variability, an increase in positive association between these disclosures and capital market disclosure incentives, and a continuing but decreased effect of proprietary costs on segment profitability disclosures. We interpret our results as indicating that SFAS No. 131 increased the transparency of reported segment profitability, allowed firms that depend more on external financing to disclose more about differences in segment profitability, but continued to allow managers of high proprietary cost firms some ability to conceal competitively harmful information about differences in segment profitability. Our results add to the existing findings on the effects of SFAS No. 131 on segment disclosure (e.g., Berger and Hann 2003a; Herrmann and Thomas 2000; Street et al. 2000) by providing evidence SFAS No. 131 increased information about operating diversity even for M-M firms that did not report more segments after SFAS No. 131. 


\section{Acknowledgments}

We wish to thank participants at workshops at the University of Kansas, the University of

Kentucky, Louisiana State University, and the University of Wisconsin. We also thank

Rob Ingram, Gary Taylor, and Paul Zarowin. 


\section{References}

Berger, P.G. and R. Hann. (2003a). "The Impact of SFAS No. 131 on Information and Monitoring.” Journal of Accounting Research 41, 163-223. .(2003b). "Segment Profitability and the Proprietary Costs of

Disclosure.” Working paper, University of Southern California.

Chen, P.F. and G. Zhang. (2003). "Heterogeneous Investment Opportunities in Multiplesegment Firms and the Incremental Value Relevance of Segment Accounting Data.” The Accounting Review 78, 397-428.

Cormier, D. and M. Magnan. (2003). “Environmental Reporting Management: A Continental European Perspective.” Journal of Accounting and Public Policy 22, 43-62.

Ettredge, M., S.Y. Kwon and D. Smith. (2002). "Security Market Effects Associated with SFAS No. 131 Reported Business Segments.” Review of Quantitative Finance and Accounting $18,323-344$.

Ettredge, M., S.Y. Kwon, D. Smith, and P. Zarowin. (2005). “The Impact of SFAS No. 131 Business Segment Data on the Market's ability to Anticipate Future Earnings.” The Accounting Review 80, 773-804.

Fama, E. F. and J.D. MacBeth. (1973). “Risk, Return and Equilibrium - Empirical Tests,” The Journal of Political Economy 81, 607-636.

Fields, T., T. Lys and L. Vincent. (2001). “Empirical Research in Accounting Choice.” Journal of Accounting and Economics 31, 255-307.

Financial Accounting Standards Board (FASB). (1976). Statement of Financial Accounting Standards No. 14: Financial Reporting for Segments of a Business Enterprise, Norwalk, CT.: FASB. 
. (1996). Exposure Draft: Proposed Statement of Financial

Accounting Standards: Reporting Disaggregated Information about a Business

Enterprise, Financial Accounting Series Norwalk, CT.: FASB.

. (1997). Statement of Financial Accounting Standards No.

131: Disclosures about Segments of an Enterprise and Related Information. Norwalk, CT.: FASB. . (2005). Proposed FASB Staff Position No. 131-a:

Determining Whether Operating Segments Have "Similar Economic Characteristics" under Paragraph 17 of FASB Statement No. 131, Disclosures about Segments of an Enterprise and Related Information Norwalk, CT. FASB.

Foster, G. (1986). Financial Statement Analysis. $2^{\text {nd }}$ edition. Englewood Cliffs, NJ: Simon \& Schuster, Inc.

Frankel, R., M. McNichols, and P. Wilson. (1995). “Discretionary Disclosure and External Financing." The Accounting Review 70, 135-150.

Gitlow, H.S., A. Oppenheim, and R. Oppenheim. (1989). Tools and Methods for the Improvement of Quality. Homewood IL: Irwin.

Harris, M.S. (1998). “The Association Between Competition and Managers’ Business Segment Reporting Decisions.” Journal of Accounting Research 36, 111-28.

Herrmann, D., and W. Thomas. (2002). “An Analysis of Segment Disclosures under SFAS No.

131 and SFAS No. 14.” Accounting Horizons 14, 287-302.

Knutson, P.H. (1993). Financial Reporting in the 1990s and Beyond. Charlottesville, VA:

AIMR.

Martin, J.D., and A. Sayrak. (2003). “Corporate Diversification and Shareholder Value: A Survey of Recent Literature.” Journal of Corporate Finance 9, 37-57. 
McPartland, N.A. (2001). Q\&A 131--Segment Information: Guidance on Applying Statement 131, FASB. September.

Schrand C.M., and R. E. Verrecchia. (2002). "Disclosure Choice and Cost of Capital: Evidence from Underpricing in Initial Public Offerings.” Working paper, University of Pennsylvania.

Sprouse, R. (1969). “Diversified Views About Diversified Companies.” Journal of Accounting Research 7, 137-159.

Street, D., N. Nichols, and S. Gray. (2000). "Segment Disclosures Under SFAS No. 131: Has Business Segment Reporting Improved?” Accounting Horizons 14, 259-285.

Taub, S. A. (2004). Remarks at the University of Southern California, Leventhal School of Accounting. www.sec.gov/news/speech/spch052704sat.htm.

Verrecchia, R. (2001). “Essays on Disclosure," Journal of Accounting and Economics 32, 97180. 
Table 1. Sample Selection Procedure

\begin{tabular}{|l|l|l|l|l|l|l|l|l|}
\hline $\begin{array}{c}\text { Sample selection } \\
\text { criteria }\end{array}$ & 1994 & 1995 & 1996 & 1997 & 1998 & 1999 & 2000 & Total \\
\hline $\begin{array}{l}\text { A. Number of firms } \\
\text { whose segments are } \\
\text { defined as business } \\
\text { segments }\end{array}$ & 5,248 & 5,827 & 6,307 & 6,632 & 7,473 & 7,838 & 7,903 & 47,228 \\
\hline $\begin{array}{l}\text { B. Number of firms } \\
\text { that disclosed two } \\
\text { or more segments in } \\
\text { the post-131 period }\end{array}$ & 4,676 & 5,487 & 5,845 & 5,763 & 5,828 & 5,311 & 5,676 & 38,586 \\
\hline $\begin{array}{l}\text { C. Number of firms } \\
\text { for which required } \\
\text { financial statements } \\
\text { data (e.g., segment } \\
\text { operating earnings } \\
\text { and segment sales) } \\
\text { are available }\end{array}$ & 4,492 & 5,245 & 5,604 & 5,557 & 5,587 & 5,587 & 4,964 & 36,407 \\
\hline $\begin{array}{l}\text { D. Number of } \\
\text { qualifying firms } \\
\text { that existed in both } \\
\text { pre-131 and post- } \\
131 \text { period }\end{array}$ & 4,277 & 5,076 & 5,540 & 5,418 & 5,359 & 4,624 & 4,626 & 34,920 \\
\hline $\begin{array}{l}\text { E. Number of firms } \\
\text { becoming multi- } \\
\text { segment after } \\
\text { adoption of SFAS } \\
\begin{array}{l}\text { No. } 131 \\
\text { (S-M Firms ) }\end{array}\end{array}$ & 3,244 & 3,912 & 4,247 & 4,218 & 4,198 & 3,497 & 3,560 & 26,876 \\
\hline $\begin{array}{l}\text { F. M-M Firms } \\
\text { Test Sample c }\end{array}$ & $\mathbf{1 , 0 3 3}$ & $\mathbf{1 , 1 6 4}$ & $\mathbf{1 , 2 9 3}$ & $\mathbf{1 , 2 0 0}$ & $\mathbf{1 , 1 6 1}$ & $\mathbf{1 , 1 2 7}$ & $\mathbf{1 , 0 6 6}$ & $\mathbf{8 , 0 4 4}$ \\
\hline
\end{tabular}

${ }^{a}$ Segment data are obtained from the Segment Item Value File, which is a subset of the COMPUSTAT Business Information File, which is a companion to the Industrial Annual

Files. The Business Information File consists of nine subset files such as Segment Customers

File, Segment Products File, and Segment Detail File as well as Segment Item Value File.

Based on the segment definition provided by Compustat Segment Item Files, we include firm-years only if a segment is defined as a business segment.

${ }^{\mathrm{b}}$ The S-M sample firms did not disclose segment data in the pre-SFAS No. 131 period, but did disclose multiple segments in at least one year after SFAS No. 131 became effective. Thus 
they are single segment disclosers in the pre- period and multiple segment disclosers in the post- SFAS No. 131 period.

${ }^{\mathrm{c}}$ The M-M sample includes firms that disclosed segment data in 1996 and in at least one year after SFAS No. 131 became effective. Thus they are multiple segment disclosers in both the pre- and post- SFAS No. 131 periods. Firms that disclosed multiple segments in one or more years of the pre-SFAS No. 131 period, but did not disclose multiple segments in the post period, are dropped from the M-M sample. 
Table 2. Descriptive Statistics for Continuous Explanatory Variables:

Pre-SFAS No. 131 Period mean/(median)/standard deviation

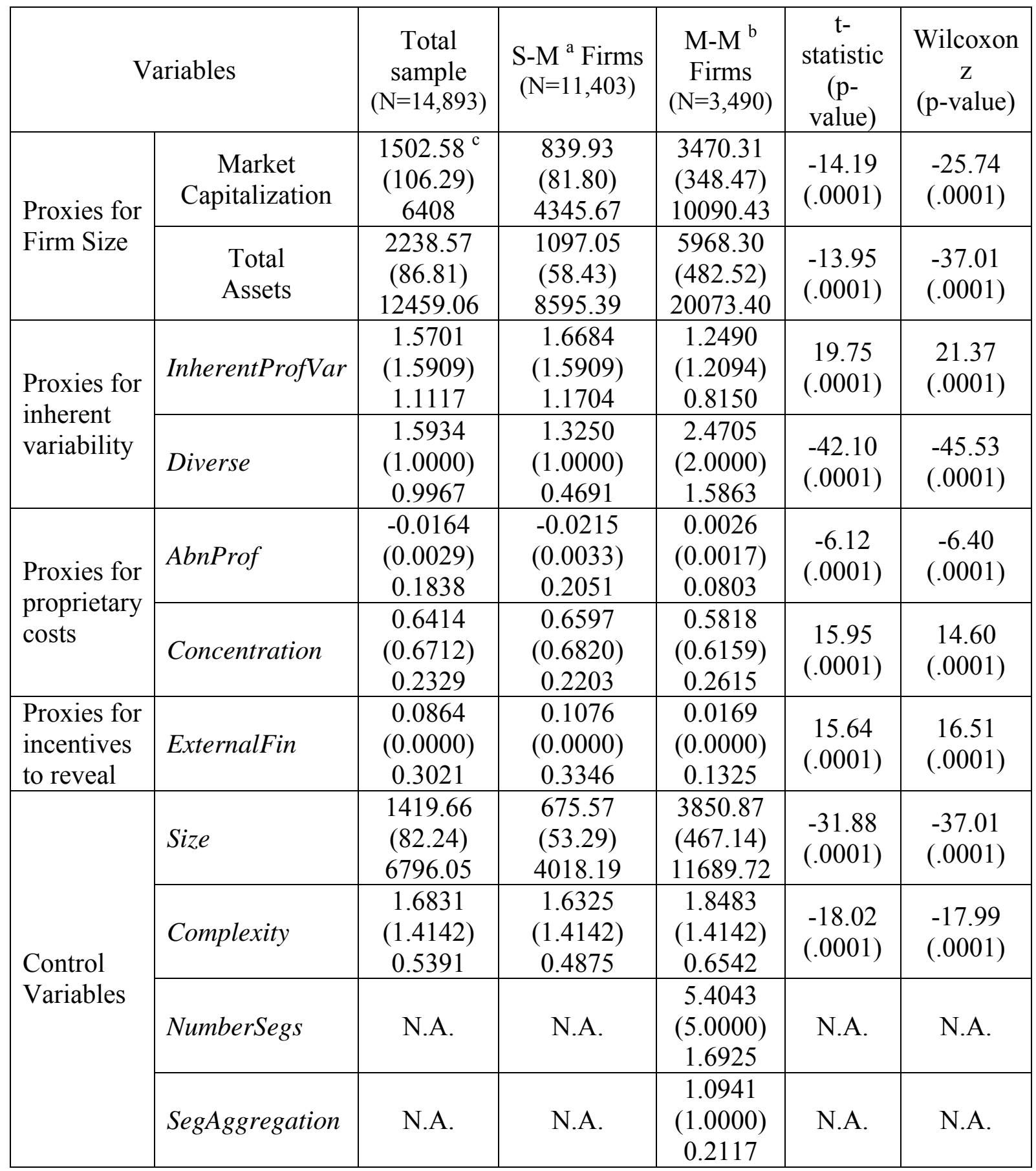

(continued) 
${ }^{\mathrm{a}}$ The S-M sample firms did not disclose segment data in the pre-SFAS No. 131 period, but did disclose multiple segments in at least one year after SFAS No. 131 became effective. Thus they are single segment reporters in the pre- period and multiple segment reporters in the post- SFAS No. 131 period.

${ }^{\mathrm{b}}$ The M-M sample includes firms that disclosed segment data in 1996 and in at least one year after SFAS No. 131 became effective. Thus they are multiple segment reporters in both the pre- and post- SFAS No. 131 periods. Firms that disclosed multiple segments in one or more years of the pre-SFAS No. 131 period, but did not disclose multiple segments in the postperiod, are dropped from the M-M sample.

${ }^{c}$ Each table cell describing the total sample or S-M or M-M firms contains the mean / (median) / standard deviation.

InherentProfVar $=$ the range of the means of return on sales for single segment firms in all four-digit SIC code industries reported as segments, weighted using the relative size of the segments. This is a proxy for the inherent variability of earnings in the industries in which a firm operates.

Diverse $=$ the number of different two-digit SIC industries in which a firm operates. This is a proxy for the inherent variability of earnings arising from the variety of industries in which a firm operates.

AbnProf $=$ the industry-adjusted measure of profits,

$$
\operatorname{AVGROA}_{i t}-1 /(\mathrm{J}-1) \sum_{j \neq i, j=1, J} \text { AVGROA }_{i t}
$$

where $A V G R O A_{i t}$ is the three-year average of ROA for firm $i$ at $t$, and $1 /(\mathrm{J}-1) \Sigma_{j \neq i, j=1, J}$ $A V G R O A_{i t}$ for $J$ firms in the industry in which firm $i$ operates is the industry average of three-year average of ROA, excluding firm i's average of ROA. This variable captures abnormal profits that attract entrants. 
Concentration $=$ the weighted average of four-firm concentration ratios for the four-digit SIC code industries matched with the firm's disclosed segments by Compustat. Each industry concentration ratio is weighted by the ratio of the matched segment's revenue divided by corporate revenue for that year.

ExternalFin $=$ the net amount of capital a firm raises through debt or equity issuance in the two years after year $t$, calculated as the sum of net equity financing from the statement of cash flows and net debt financing from the statement of cash flows over two-years period. This variable captures the need for external financing, proxying for a countervailing incentive to reveal variability. We obtain information on the gross amount of securities issuances and retirements/repurchases from the statement of cash flows.

Size $=$ the natural logarithm of total corporate revenues for each year. Descriptive statistics for Size are given prior to logarithmic transformation.

Complexity $=$ the square root of the sum of the number of products that a firm produces and the number of geographic areas in which the firm operates. The numbers of products are increased by 'one' if a disclosed principal product has sales (i.e., PSALE data item in Segment Products File is greater than zero). The number of geographical areas is the number of non-zero GARE data items in Segment Customers File.

NumberSegs $=$ the number of reported segments disclosed in a given year. Data are obtained from Compustat's Segment Item Value File.

SegAggregation $=$ the number of four-digit SIC codes Compustat assigns a firm, divided by the number of segments the firm reports each year. 
Table 3. Comparisons of the Changes in Number of Segments and Changes in Cross-Segment Profit Variability for the Pre-SFAS No. 131 Versus the Post-SFAS No.131 Period

\begin{tabular}{|c|c|c|c|c|c|c|}
\hline & \multicolumn{3}{|c|}{ NumberSegs ${ }^{\text {a }}$} & \multicolumn{3}{|c|}{ ReptdProfVar $^{\mathrm{b}}$} \\
\hline & Pre-131 & Post-131 & $\begin{array}{c}\text { t-statistics } \\
\text { (p-value) }\end{array}$ & Pre-131 & Post-131 & $\begin{array}{c}\text { t-statistics } \\
\text { (p-value) }\end{array}$ \\
\hline $\begin{array}{c}\text { S-M } \\
\text { Sample }^{\text {c }}\end{array}$ & 1 & $\begin{array}{l}3.584^{\mathrm{d}} \\
(3.00)\end{array}$ & $\begin{array}{l}136.43 \\
(.0001)\end{array}$ & - & $\begin{array}{l}0.9441 \\
(.0459)\end{array}$ & - \\
\hline \multirow{5}{*}{$\begin{array}{c}\text { M-M } \\
\text { Sample }^{\text {e }}\end{array}$} & 2 & $\begin{array}{c}2.60 \\
(3.00)\end{array}$ & $\begin{array}{c}2.45 \\
(.0705)\end{array}$ & $\begin{array}{c}0.1019 \\
(0.0914)\end{array}$ & $\begin{array}{c}0.1775 \\
(0.1131)\end{array}$ & $\begin{array}{c}0.73 \\
(.5902)\end{array}$ \\
\hline & 3 & $\begin{array}{c}3.51 \\
(3.00)\end{array}$ & $\begin{array}{c}4.02 \\
(.0001)\end{array}$ & $\begin{array}{c}0.5122 \\
(0.1188)\end{array}$ & $\begin{array}{c}0.4756 \\
(0.2036)\end{array}$ & $\begin{array}{c}-0.22 \\
(.8231)\end{array}$ \\
\hline & 4 & $\begin{array}{c}4.65 \\
(4.00)\end{array}$ & $\begin{array}{c}7.18 \\
(.0001)\end{array}$ & $\begin{array}{c}0.4263 \\
(0.1204)\end{array}$ & $\begin{array}{c}0.9542 \\
(0.1729)\end{array}$ & $\begin{array}{c}3.77 \\
(.0002)\end{array}$ \\
\hline & 5 & $\begin{array}{c}5.02 \\
(5.00)\end{array}$ & $\begin{array}{c}0.48 \\
(.6280) \\
\end{array}$ & $\begin{array}{c}0.8775 \\
(0.1902) \\
\end{array}$ & $\begin{array}{c}1.4190 \\
(0.1939) \\
\end{array}$ & $\begin{array}{c}2.95 \\
(.0034) \\
\end{array}$ \\
\hline & $\geq 6$ & $\begin{array}{c}5.71 \\
(6.00)\end{array}$ & $\begin{array}{l}-12.77 \\
(.0001)\end{array}$ & $\begin{array}{c}0.8285 \\
(0.2053)\end{array}$ & $\begin{array}{c}1.3968 \\
(0.2464)\end{array}$ & $\begin{array}{c}3.81 \\
(.0002)\end{array}$ \\
\hline
\end{tabular}

${ }^{a}$ NumberSegs is the number of reported segments disclosed in a given year. Data are obtained from Compustat’s Segment Item Value File.

${ }^{\mathrm{b}}$ ReptdProfVar is the range of a firm's segment return on sales for each year: the largest return on sales minus the smallest. Return on sales equals a segment's operating profit, as defined by the firm, divided by the segment's total revenue.

${ }^{\mathrm{c}}$ The S-M sample firms did not disclose segment data in the pre-SFAS No. 131 period, but did disclose multiple segments in at least one year after SFAS No. 131 became effective. Thus they are single segment reporters in the pre- period and multiple segment reporters in the post- SFAS No. 131 period.

${ }^{d}$ Each table cell (other than for t-statistics) contains the sub-sample mean / (median).

${ }^{\mathrm{e}}$ The M-M sample includes firms that disclosed segment data in 1996 and in at least one year after SFAS No. 131 became effective. Thus they are multiple segment reporters in both the pre- and post- SFAS No. 131 periods. Firms that disclosed multiple segments in one or more 
years of the pre-SFAS No. 131 period, but did not disclose multiple segments in the postperiod, are dropped from the M-M sample. 
Table 4. Descriptive Statistics for the Dependent Variable and the Test Sample (M-M Firms) by Sub-Period, and Tests for Sub-Period Comparisons

\begin{tabular}{|c|c|c|c|c|c|c|c|}
\hline Sample & $\begin{array}{c}\text { Number of } \\
\text { observations }\end{array}$ & Mean & Median & $\begin{array}{c}\text { Standard } \\
\text { Deviation }\end{array}$ & Min. & Max. $^{a}$ & $\begin{array}{c}\text { Test } \\
\text { statistics }\end{array}$ \\
\hline ReptdProfVar ${ }^{\mathrm{b}}$ & & & & & & & \\
\hline 1994-1996 & 3,490 & 0.701 & 0.164 & 1.632 & 0.013 & 7.9543 & $\begin{array}{l}12.51^{\mathrm{c}} \\
(.0001)\end{array}$ \\
\hline $1998-2000$ & 3,354 & 1.488 & 0.240 & 3.271 & 0.004 & 13.1187 & $\begin{array}{l}10.80^{\mathrm{d}} \\
(.0001)\end{array}$ \\
\hline $\begin{array}{c}1994-1996 \& \\
1998-2000\end{array}$ & 6,844 & 0.998 & 0.104 & 2.906 & 0.004 & 13.1187 & N.A. \\
\hline
\end{tabular}

${ }^{a}$ Maximums greater than 1.0 occur because some firms report negative as well as positive segment profits. It can have a value greater than 1 since a firm can have negative as well as positive segment profits. In addition, a firm can have segment ROSs less than 1, which magnifies the range of segment ROSs. The negative value of ROS can occur in the circumstance where a segment has a high operating leverage with low sales and high operating expenses. $31.69 \%$ of our sample has negative segment profits and $6.34 \%$ of the sample has the value greater than 1 . We replicate our empirical analyses by restricting the value of ReptProfVar within the range of \pm 1 , but the results remain unchanged.

${ }^{\mathrm{b}}$ ReptdProfVar is the range of a firm's segment return on sales for each year: the largest return on sales minus the smallest. Return on sales equals a segment's operating profit, as defined by the firm, divided by the segment's total revenue.

${ }^{c}$ t-statistic (p-value) for test whether mean for 1994-1996 equals mean for 1998-2000

${ }^{d}$ Wilcoxon z-statistic (p-value) for test whether median for 1994-1996 equals mean for 19982000. 
Table 5. Results of Model (3) Regression with ReptProfVar ${ }^{\text {a }}$ as Dependent Variable where FAS131 Provides Evidence for Tests of Hypothesis H1

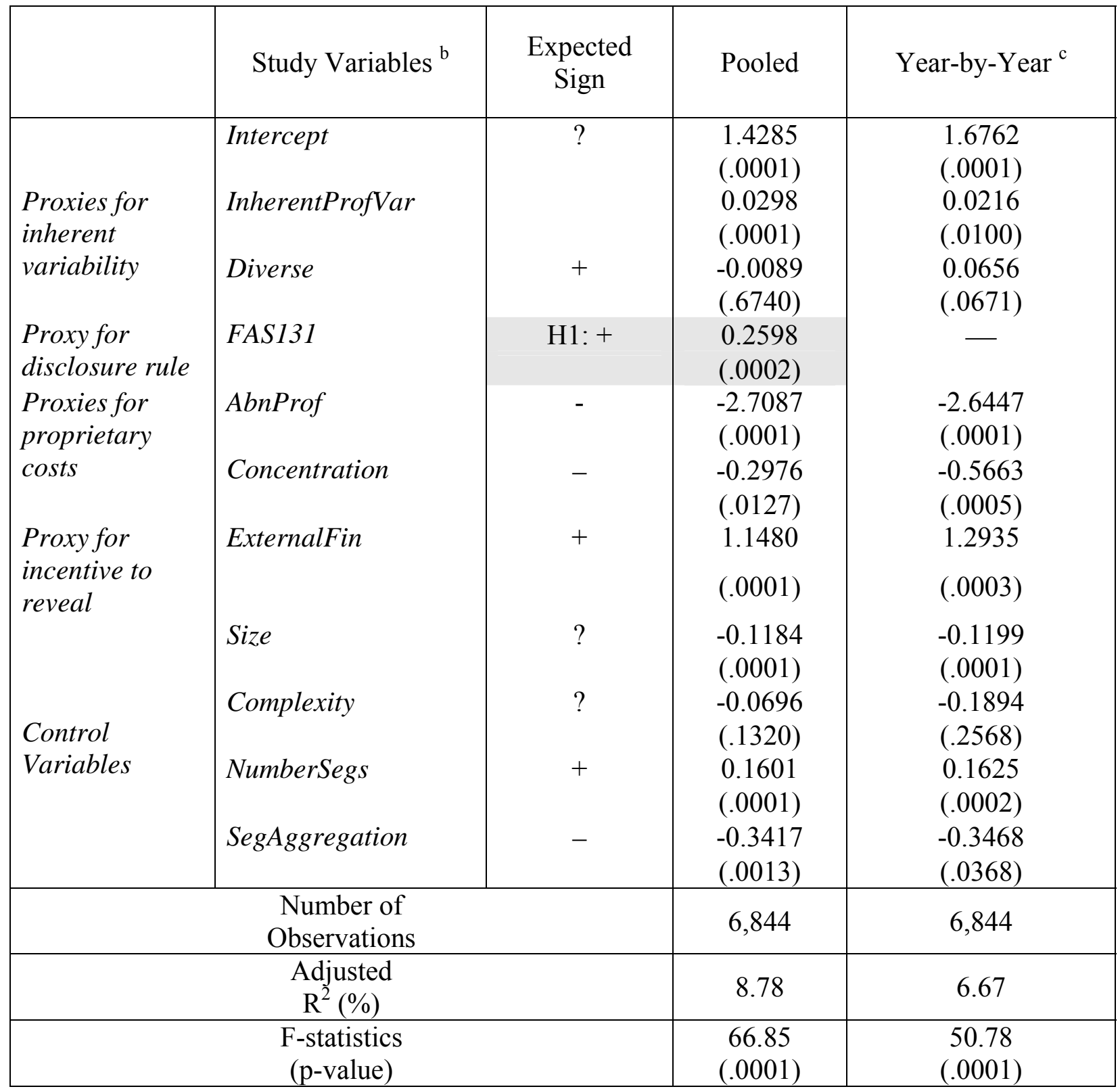

a Equals the range of a firm's segment return on sales (RROS) for each year: highest segment return on sales minus the lowest.

${ }^{\mathrm{b}}$ See Table 2 for variable definitions. 
${ }^{\mathrm{c}}$ We report the Fama-MacBeth (1973) regression results in yearly regressions. The t-statistics of the mean coefficients are computed as the mean coefficient divided by the mean standard error of the six annual regressions. 
Table 6. Model (3 modified) Regression Results: Tests of Shift in Coefficients between Preversus Post- SFAS No. 131 Periods

\begin{tabular}{|c|c|c|c|c|c|c|}
\hline \multirow[b]{2}{*}{ Study Variables ${ }^{\mathrm{a}}$} & \multicolumn{3}{|c|}{ Model (3a) } & \multicolumn{3}{|c|}{ Model (3b) } \\
\hline & Pre-131 & Post-131 & $\begin{array}{c}\text { Test of } \\
\text { Difference }\end{array}$ & Pre-131 & Post-131 & $\begin{array}{c}\text { Test of } \\
\text { Difference }^{2}\end{array}$ \\
\hline Intercept & $\begin{array}{l}1.0951 \\
(.0001)\end{array}$ & $\begin{array}{l}2.3074 \\
(.0001)\end{array}$ & - & $\begin{array}{l}1.1782 \\
(.0001)\end{array}$ & $\begin{array}{l}2.4172 \\
(.0001)\end{array}$ & - \\
\hline $\begin{array}{r}\text { InherentProfVar } \\
\text { Expected sign }\end{array}$ & $\begin{array}{l}0.0135 \\
(.0367)\end{array}$ & $\begin{array}{l}0.0304 \\
(.0002)\end{array}$ & $\begin{array}{c}2.06 * * \\
(.0392) \\
\text { H2: }+\end{array}$ & N.A. & N.A. & - \\
\hline $\begin{array}{l}\text { Diverse } \\
\qquad \text { Expected sign }\end{array}$ & N.A. & N.A. & - & $\begin{array}{l}-0.0219 \\
(.2344)\end{array}$ & $\begin{array}{l}0.1150 \\
(.0059)\end{array}$ & $\begin{array}{c}3.35 * * * \\
(.0008) \\
\mathrm{H} 2:+\end{array}$ \\
\hline $\begin{array}{l}\text { AbnProf } \\
\text { Expected sign }\end{array}$ & $\begin{array}{l}-2.6850 \\
(.0001)\end{array}$ & $\begin{array}{l}-2.6203 \\
(.0001)\end{array}$ & $\begin{array}{c}0.15 \\
(.8846) \\
\text { H3: }+\end{array}$ & $\begin{array}{l}-2.6611 \\
(.0001)\end{array}$ & $\begin{array}{l}-2.4821 \\
(.0001)\end{array}$ & $\begin{array}{c}0.01 \\
(.9902) \\
\text { H3: }+\end{array}$ \\
\hline $\begin{array}{l}\text { Concentration } \\
\text { Expected sign }\end{array}$ & $\begin{array}{r}-0.3175 \\
(.0017)\end{array}$ & $\begin{array}{l}-0.7774 \\
(.0004)\end{array}$ & $\begin{array}{c}-0.86 \\
(.3915) \\
\text { H3: }+\end{array}$ & $\begin{array}{l}-0.3505 \\
(.0008)\end{array}$ & $\begin{array}{l}-0.7566 \\
(.0006)\end{array}$ & $\begin{array}{c}-0.55 \\
(.5800) \\
\text { H3: }+\end{array}$ \\
\hline $\begin{array}{l}\text { ExternalFin } \\
\text { Expected sign }\end{array}$ & $\begin{array}{l}0.8367 \\
(.0001)\end{array}$ & $\begin{array}{l}1.7420 \\
(.0004)\end{array}$ & $\begin{array}{c}1.96 * * \\
(.0499) \\
\mathrm{H} 4:+\end{array}$ & $\begin{array}{l}0.8537 \\
(.0001)\end{array}$ & $\begin{array}{l}1.8291 \\
(.0002)\end{array}$ & $\begin{array}{c}2.13 * * \\
(.0329) \\
\mathrm{H} 4:+\end{array}$ \\
\hline Size & $\begin{array}{r}-0.0777 \\
(.0001)\end{array}$ & $\begin{array}{l}-0.1542 \\
(.0001)\end{array}$ & $\begin{array}{l}-2.44 * * \\
(.0147)\end{array}$ & $\begin{array}{r}-0.0833 \\
(.0001)\end{array}$ & $\begin{array}{l}-0.1710 \\
(.0001)\end{array}$ & $\begin{array}{c}-2.82 * * * \\
(.0049)\end{array}$ \\
\hline Complex & $\begin{array}{c}-0.3260 \\
(.0001)\end{array}$ & $\begin{array}{l}-0.0725 \\
(.3541)\end{array}$ & $\begin{array}{l}3.22 * * * \\
(.0013)\end{array}$ & $\begin{array}{c}-0.3208 \\
(.0001)\end{array}$ & $\begin{array}{l}-0.0401 \\
(.6106)\end{array}$ & $\begin{array}{l}3.49 * * * \\
(.0001)\end{array}$ \\
\hline NumberSegs & $\begin{array}{l}0.2263 \\
(.0001)\end{array}$ & $\begin{array}{l}0.1133 \\
(.0001)\end{array}$ & $\begin{array}{l}-2.05 * * \\
(.0405)\end{array}$ & $\begin{array}{l}0.2375 \\
(.0001)\end{array}$ & $\begin{array}{l}0.0873 \\
(.0007)\end{array}$ & $\begin{array}{c}-3.03 * * * \\
(.0001)\end{array}$ \\
\hline SegAggregation & $\begin{array}{c}-0.4178 \\
(.0012)\end{array}$ & $\begin{array}{c}-0.2564 \\
(.1257) \\
\end{array}$ & $\begin{array}{c}1.47 \\
(.1223) \\
\end{array}$ & $\begin{array}{r}-0.3939 \\
(.0024)\end{array}$ & $\begin{array}{l}-0.3025 \\
(.0734) \\
\end{array}$ & $\begin{array}{c}1.58 \\
(.1134) \\
\end{array}$ \\
\hline $\begin{array}{c}\text { Number of } \\
\text { observations }\end{array}$ & 3,490 & 3,354 & - & 3,490 & 3,354 & - \\
\hline $\begin{array}{l}\text { Adjusted } \\
\mathrm{R}^{2}(\%)\end{array}$ & 9.09 & 6.17 & - & 9.02 & 6.01 & - \\
\hline $\begin{array}{l}\text { F-statistics } \\
\text { (p-value) }\end{array}$ & $\begin{array}{c}44.62 \\
(.0001)\end{array}$ & $\begin{array}{c}38.18 \\
(.0001)\end{array}$ & - & $\begin{array}{c}44.21 \\
(.0001)\end{array}$ & $\begin{array}{c}35.41 \\
(.0001)\end{array}$ & - \\
\hline
\end{tabular}

$* / * * * * *$ significant at the $10 \% / 5 \% / 1 \%$ level

${ }^{\text {a }}$ See Table 2 for variable definitions. 
${ }^{b}$ t-statistics (p-values). To determine significance levels for tests of shifts in coefficients, we estimated a pooled regression (not tabulated) with a POST-131 dichotomous variable interacted with each term. 
Table 7. Descriptive Statistics for Alternative Specifications of ReptdProfVar that Incorporate Measures of the Importance of Segment Size, and Tests for Sub-Period Comparisons

\begin{tabular}{|c|c|c|c|c|c|c|c|}
\hline Sample & $\begin{array}{c}\text { Number of } \\
\text { observations }\end{array}$ & Mean & Median & $\begin{array}{c}\text { Standard } \\
\text { Deviation }\end{array}$ & Min. & Max. $^{\mathrm{a}}$ & $\begin{array}{c}\text { Test } \\
\text { statistics }\end{array}$ \\
\hline \multicolumn{8}{|l|}{ ReptdProfVar_LrgAvg ${ }^{\mathrm{b}}$} \\
\hline 1994-1996 & 3,490 & 0.167 & -0.097 & 1.332 & -7.009 & 6.818 & $\begin{array}{l}7.93^{\mathrm{c}} \\
(.0001)\end{array}$ \\
\hline $1998-2000$ & 3,354 & 0.606 & -0.034 & 2.926 & -6.355 & 8.292 & $\begin{array}{l}15.17^{\mathrm{d}} \\
(.0001)\end{array}$ \\
\hline \multicolumn{8}{|l|}{ ReptdProfVar_Xsml ${ }^{\mathrm{e}}$} \\
\hline 1994-1996 & 3,490 & 0.124 & 0.023 & 0.222 & 0.013 & 1.269 & $\begin{array}{c}17.41 \\
(.0001)\end{array}$ \\
\hline $1998-2000$ & 3,354 & 0.872 & 0.130 & 2.479 & 0.011 & 13.281 & $\begin{array}{c}25.40 \\
(.0001)\end{array}$ \\
\hline \multicolumn{8}{|l|}{ ReptdProfVar_Le $1^{\mathrm{f}}$} \\
\hline 1994-1996 & 3,490 & 0.311 & 0.165 & 0.329 & 0.013 & 1.000 & $\begin{array}{c}11.50 \\
(.0001)\end{array}$ \\
\hline $1998-2000$ & 3,354 & 0.409 & 0.240 & 0.376 & 0.004 & 1.000 & $\begin{array}{c}10.54 \\
(.0001)\end{array}$ \\
\hline
\end{tabular}

${ }^{a}$ Maximums greater than 1.0 occur because some firms report negative as well as positive segment profits. It can have a value greater than 1 since a firm can have negative as well as positive segment profits. In addition, a firm can have segment ROSs less than 1, which magnifies the range of segment ROSs. The negative value of ROS can occur in the circumstance where a segment has a high operating leverage with low sales and high operating expenses. $31.69 \%$ of our sample has negative segment profits and $6.34 \%$ of the sample has the value greater than

${ }^{\mathrm{b}}$ ReptdProfVar_LrgAvg is the difference between ROS of the largest segment and the average of segment ROS. This variable can have negative values because ROS of the largest segment may be less than the average of segment ROS.

${ }^{c}$ t-statistic (p-value) for test whether mean for 1994-1996 equals mean for 1998-2000

${ }^{d}$ Wilcoxon z-statistic (p-value) for test whether median for 1994-1996 equals mean for 19982000. 
${ }^{\mathrm{e}}$ ReptdProfVar_Xsml is the range in a firm's segment return on sales for each year after dropping the smallest segment by segment sales.

${ }^{\mathrm{f}}$ ReptdProfVar_Le1 is the range in a firm's segment return on sales for each year with truncation at 1 if the value is greater than 1. 
Table 8. Results of Model (3) Regression: Sensitivity Analyses Using Alternative Measures of the Dependent Variable

\begin{tabular}{|c|c|c|c|c|c|c|c|}
\hline \multirow{3}{*}{$\begin{array}{c}\text { Explanatory } \\
\text { Variables }\end{array}$} & \multirow{3}{*}{$\begin{array}{l}\text { Expected } \\
\text { Sign }\end{array}$} & \multicolumn{6}{|c|}{ Dependent Variables } \\
\hline & & \multicolumn{2}{|c|}{ ReptdProfVar_LrgAvga } & \multicolumn{2}{|c|}{ ReptdProfVar_Xsml ${ }^{\mathrm{b}}$} & \multicolumn{2}{|c|}{ ReptdProfVar_LeI ${ }^{\mathrm{c}}$} \\
\hline & & $\begin{array}{l}\text { Pooled } \\
\text { Sample }\end{array}$ & $\begin{array}{l}\text { Year-by- } \\
\text { Year d }^{\mathrm{d}}\end{array}$ & $\begin{array}{l}\text { Pooled } \\
\text { Sample }\end{array}$ & $\begin{array}{c}\text { Year-by- } \\
\text { Year }{ }^{\mathrm{d}}\end{array}$ & $\begin{array}{l}\text { Pooled } \\
\text { Sample }\end{array}$ & $\begin{array}{l}\text { Year-by- } \\
\text { Year }^{d}\end{array}$ \\
\hline \multirow[t]{2}{*}{ Intercept } & $?$ & 0.7455 & 0.9382 & 0.2565 & 0.6451 & 0.4495 & 0.3863 \\
\hline & & $(.0001)$ & $(.0003)$ & $(.0001)$ & $(.1168)$ & $(.0001)$ & $(.0001)$ \\
\hline \multirow[t]{2}{*}{ InherentProfVar } & + & 0.0171 & 0.0169 & 0.0132 & 0.0071 & 0.0759 & 0.0091 \\
\hline & & $(.0004)$ & $(.0181)$ & $(.0004)$ & $(.0552)$ & $(.0001)$ & $(.0001)$ \\
\hline \multirow[t]{2}{*}{ Diverse } & + & -0.0131 & -0.0167 & -0.0168 & 0.0455 & 0.0072 & 0.0141 \\
\hline & & $(.4857)$ & $(.4834)$ & $(.2380)$ & $(.0607)$ & $(.0102)$ & $(.2359)$ \\
\hline \multirow[t]{2}{*}{ FAS131 } & $\mathrm{H} 1:+$ & 0.3531 & - & 0.2355 & - & 0.0301 & - \\
\hline & & $(.0001)$ & & $(.0001)$ & & $(.0009)$ & \\
\hline \multirow[t]{2}{*}{ AbnProf } & - & -3.7138 & -3.5448 & -0.7605 & -0.6438 & -0.4850 & -0.4993 \\
\hline & & $(.0001)$ & $(.0001)$ & $(.0015)$ & $(.0077)$ & $(.0001)$ & $(.0001)$ \\
\hline \multirow[t]{2}{*}{ Concentration } & - & -0.0714 & -0.0839 & -0.0370 & -0.3199 & -0.0973 & -0.1310 \\
\hline & & (.4974) & $(.4802)$ & $(.6441)$ & $(.0003)$ & $(.0001)$ & $(.0001)$ \\
\hline \multirow[t]{2}{*}{ ExternalFin } & + & 1.2628 & 1.4124 & 0.4591 & 0.6466 & 0.1247 & 0.1244 \\
\hline & & $(.0001)$ & $(.0001)$ & $(.0059)$ & $(.0278)$ & $(.0001)$ & $(.0187)$ \\
\hline \multirow[t]{2}{*}{ Size } & $?$ & -0.1255 & -0.1296 & -0.0866 & -0.0768 & -0.0248 & -0.0235 \\
\hline & & $(.0001)$ & $(.0001)$ & $(.0001)$ & $(.0001)$ & $(.0001)$ & $(.0001)$ \\
\hline \multirow[t]{2}{*}{ Complexity } & $?$ & 0.0794 & -0.0113 & -0.0140 & -0.0612 & -0.0184 & -0.0617 \\
\hline & & $(.0514)$ & $(.0905)$ & $(.6515)$ & $(.2812)$ & $(.0023)$ & $(.4864)$ \\
\hline \multirow[t]{2}{*}{ NumberSegs } & + & 0.0274 & 0.0669 & 0.1676 & 0.0884 & 0.0328 & 0.0470 \\
\hline & & $(.0050)$ & $(.0256)$ & $(.0001)$ & $(.0001)$ & $(.0001)$ & $(.0001)$ \\
\hline \multirow[t]{2}{*}{ SegAggretation } & - & -0.0970 & -0.1414 & -0.1130 & -0.0985 & -0.0612 & -0.0568 \\
\hline & & $(.3000)$ & $(.3979)$ & $(.1127)$ & $(.4500)$ & $(.0001)$ & $(.0162)$ \\
\hline \multicolumn{2}{|c|}{$\begin{array}{c}\text { Number of } \\
\text { Observations }\end{array}$} & 6,844 & 6,844 & 6,844 & 6,844 & 6,844 & 6,844 \\
\hline \multicolumn{2}{|c|}{$\begin{array}{l}\text { Adjusted } \\
\mathrm{R}^{2}(\%)\end{array}$} & 6.97 & 8.05 & 12.62 & 13.28 & 17.63 & 15.60 \\
\hline \multicolumn{2}{|c|}{$\begin{array}{c}\text { F-statistics } \\
\text { (p-value) }\end{array}$} & $\begin{array}{c}52.31 \\
(.0001) \\
\end{array}$ & $\begin{array}{c}60.42 \\
(.0001)\end{array}$ & $\begin{array}{c}99.84 \\
(.0001) \\
\end{array}$ & $\begin{array}{l}104.90 \\
(.0001)\end{array}$ & $\begin{array}{l}147.46 \\
(.0001) \\
\end{array}$ & $\begin{array}{l}130.48 \\
(.0001)\end{array}$ \\
\hline
\end{tabular}

${ }^{a}$ ReptProfVar_LrgAvg is the difference between $R O S$ of the largest segment and the average of segment ROS. This variable can have negative values because ROS of the largest segment may be less than the average of segment ROS.

${ }^{\mathrm{b}}$ ReptProfVar_Xsml is the range in a firm's segment return on sales for each year after dropping the smallest segment (as measured by segment sales).

${ }^{\mathrm{c}}$ ReptProfVar_Le1 is the range in a firm's segment return on sales for each year with truncation at 1 if the value is greater than 1 . 
${ }^{\mathrm{d}}$ We report the Fama-MacBeth (1973) regression results in yearly regressions. The t-statistics of the mean coefficients are computed as the mean coefficient divided by the mean standard error of the six annual regressions all multiplied by the square root of six minus one. This controls for the assumption of independence. 


\section{Notes}

${ }^{1}$ SFAS No. 14, Financial Reporting by Segments of a Business Enterprise (FASB 1976), provided segment disclosure guidelines prior to the issuance of SFAS No. 131. Analysts have described segment data as "vital" to their work and have characterized SFAS No. 14 as resulting in disclosure that did not reveal how various components of a business behave economically (Knutson 1993: 59).

${ }^{2}$ The industry approach under SFAS No. 14 (also referred to as line of business reporting) defined segments in terms of the industries in which a firm had significant business activities. The management approach under SFAS No. 131 defines segments to reflect the way the firm is managed internally. When these approaches differ, adoption of SFAS No. 131 could result in decreases, increases, or no change in numbers of reported segments. The expectation of nonincreasing changes was indicated by Air Products in its June 20, 1996 comment letter to the FASB: "One of the objectives of the proposed standard is to increase the number of segments reported. On the basis of the exposure draft's criteria for segment determination we would decrease (emphasis added) the segments reported from four to three."

${ }^{3}$ Berger and Hann (2003b) use cross-segment variability of segment profits as an explanatory variable proxying for within firm heterogeneity in segment profits.

${ }^{4}$ SFAS No. 131 (in Question 8 of Q\&A 131--Segment Information: Guidance on Applying Statement 131) states that "operating segments often exhibit similar long-term financial performance if they have similar economic characteristics. For example, similar long-term average gross margins for two operating segments would be expected if their economic characteristics were similar." The Q \& A goes on to say "that [profit margins are] used only as an example, because gross margin is a measure of profitability that is less likely to be affected 
by allocations." FASB (2005) includes gross margin as an example of a quantitative factor that might be considered for purposes of determining whether operating segments have similar economic characteristics.

${ }^{5}$ SFAS No. 131 provides no definition of how segment profits are to be computed. Instead, reported segment profits are to be the same measures the chief operating decision maker uses internally to asses performance and allocate resources. Thus segment profits need not be measured in accordance with GAAP.

${ }^{6}$ Managers also warned of competitive harm in responding to the ED preceding SFAS No. 14 (Sprouse 1969). Responding managers did not acknowledge that they might benefit from the increased disclosure of competitors.

${ }^{7}$ Control variables include the expected size of a segment's operations relative to the size of the firm, the number of industries in which the firm operates, and the heterogeneity of earnings persistence across segments.

${ }^{8}$ This variable is the same as the speed of profit adjustment variable in Harris (1998).

${ }^{9}$ Chen and Zhang's (2003) analysis does not consider the possible effect of proprietary costs.

${ }^{10}$ Comment letters responding to Issue 2 in the request for comment on the ED suggest that the criteria found in paragraphs 11-19 of the ED would force managers to redefine company segments based upon the similarity and dissimilarity of profit margins related to a company's outputs.

${ }^{11}$ Most firms report a small number of segments. In Chen and Zhang's (2003) sample of firms reporting more than one segment, $88 \%$ reported two, three, or four segments while only $12 \%$ reported five or more. Comparable results are obtained when we operationalize the dependent variable as the standard deviation of ROS rather than the range. 
${ }^{12}$ Other measures of segment profit sometimes disclosed are income after depreciation, pretax income, income before extraordinary items, and net income. None of these is reported frequently enough by firms in our sample to be used in empirical testing.

${ }^{13} \mathrm{We}$ also test an alternative to InherentProfVar. We first compute the range of ROS for singlesegment firms in each of the $\mathrm{N}$ industries. We then compute the mean of the $\mathrm{N}$ ranges. Our results using this variable are very similar to those using InherentProfVar and so we have chosen not to table these results.

${ }^{14}$ Diverse is an example of a business count measure of diversification. See Martin and Sayrak (2003) for discussion.

${ }^{15}$ SFAS No. 131 does not require segment information be provided in accordance with the same generally accepted accounting principles used to prepare consolidated financial statements. It provides some disclosure of how a firm allocates joint costs, jointly used assets, or jointly incurred liabilities to segments, and how inter-segment transfers are priced (Appendix A, paragraph 84).

${ }^{16}$ Proprietary costs also have been used to explain differences in IPO underpricing (Schrand and Verrecchia 2002) and environmental reporting (Cormier and Magnan 2003).

${ }^{17}$ Berger and Hann (2003b) also employ an industry-adjusted ROA metric to proxy for proprietary costs. The industry adjustment is based on a sample firm's main SIC code, and employs all firms in that SIC code.

${ }^{18}$ For each industry K, we used all single segment firms, available on Compustat, with primary SICs in that industry. Use of single segment firms is desirable because they are more subject to the inherent variability of profits within that specific industry, than are multiple segment firms. The latter are likely to operate in multiple industries. One downside of our procedure is that the 
single segment firms tend to be smaller than the multiple segment firms in our M-M sample. Therefore we also re-estimated abnormal profits using all firms in each industry, rather than only single segment firms. Then we repeated our regressions using the revised measures of abnormal return. Results are qualitatively unchanged.

${ }^{19}$ We use the term "competition" in a strict, economic sense (i.e. a "highly competitive" industry approaches the economic scenario of pure competition). This usage can seem counterintuitive since purely competitive producers do not advertise, unilaterally cut prices, or engage in other activities that consumers commonly think of as competitive. This is because pure competitors do not have differentiated products, and cannot individually affect aggregate supply, aggregate demand, or market price.

${ }^{20}$ To compute the concentration ratio for an industry, we use all firms available on Compustat, with primary SICs in that industry, irrespective of whether they are single segment or multiple segment firms.

${ }^{21}$ The t-statistics for the means of the coefficients (across years) are each computed as the mean coefficient divided by the mean standard error for the six annual regressions, all multiplied by the square root of the number of years minus one.

${ }^{22}$ The Segment Item Value File is a subset of the Compustat Business Information File, which is a companion to the Compustat Annual Files. Form 10-K disclosures are the primary source of the segment information in the file (confirmed by telephone call to Compustat).

${ }^{23}$ Although there are twice as many S-M firms as M-M firms, Table 2 indicates that the M-M firms are on average more than four times as large as the S-M firms.

${ }^{24}$ The post-SFAS No. 131 mean (of 5.71) is derived from a sub-sample that includes some firms previously disclosing seven or more segments. Thus the decrease in segment numbers 
was substantial for some firms. SFAS No. 131 (Par. 10) requires that an operating segment be defined as a component of an enterprise whose operating results are regularly reviewed by the enterprise's chief operating decision maker, to make decisions about resources to be allocated to the segment and assess its performance. This arguably provides some large firms the opportunity to decrease the numbers of their reported segments when adopting SFAS No. 131. In a comment letter to the SEC dated June 27, 1996, Engelhard Corp. stated: "We believe the guidance may result in an unreasonably high number of operating segments for smaller companies; larger companies may have an inherent advantage in that the chief operating decision maker may be forced by time constraints to focus on larger segments of operations." ${ }^{25}$ We attribute this increase in variance to qualitative improvements in segment data reported under SFAS No. 131. Ettredge et al. (2005) provide a discussion of these improvements in their Appendix.

${ }^{26}$ In our empirical models we employ numbers of reported segments as a control variable.

${ }^{27}$ We also experimented with an alternative measure of reported cross-segment earnings variability: range of segment return on assets. Plotting this variable against total segment assets indicated that the variable was not fully controlling for differences in firm size (see Foster 1986: 98).

${ }^{28}$ Results are basically unchanged when 1997 observations are included.

${ }^{29}$ We truncate all continuous variables at the 1 st and 99 th percentiles before estimating the models.

${ }^{30}$ Results are similar when the model is re-estimated using an alternative competitiveness measure: the concentration ratio for the firm's primary four-digit SIC industry. 
${ }^{31}$ We also assess whether the effect of proprietary cost incentives is attenuated by a firm's need for external financing by including an variable coded as the interaction between AbnProf and dummy variable coded one if ExternalFin is greater than the sample median. The insignificance of the interaction term (untabled) suggests that the effect of firm-level profitability on the dependent variable is independent of the firm's financing needs.

${ }^{32}$ To determine significance levels for tests of shifts in coefficients, we estimated a pooled regression (not tabulated) with a POST-131 dichotomous variable interacted with each term.

${ }^{33}$ Paragraph 18 of SFAS No. 131 requires separate disclosure of operating segments that account for $10 \%$ or more of total segment revenue, reported profit or loss or combined assets. 